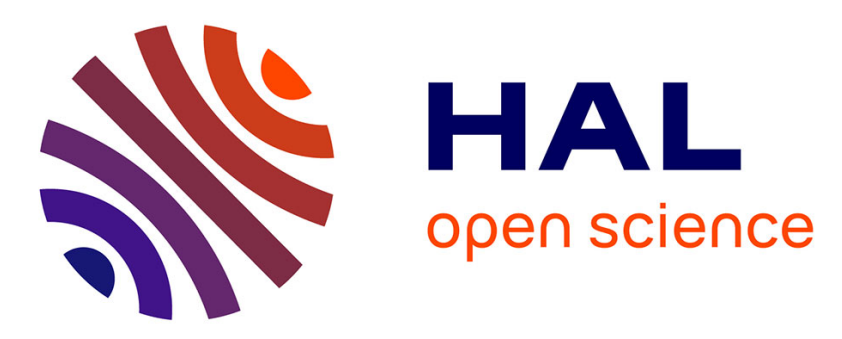

\title{
Protonation-Gated Dual Photochromism of a Chromene-Styryl Dye Hybrid
}

\author{
Daria V Berdnikova, Thomas Paululat, Gediminas Jonusauskas, Svetlana M \\ Peregudova, Olga A. Fedorova
}

\section{- To cite this version:}

Daria V Berdnikova, Thomas Paululat, Gediminas Jonusauskas, Svetlana M Peregudova, Olga A. Fedorova. Protonation-Gated Dual Photochromism of a Chromene-Styryl Dye Hybrid. Organic Letters, 2017, 19 (20), pp.5633-5636. 10.1021/acs.orglett.7b02798 . hal-01629249

\section{HAL Id: hal-01629249 \\ https://hal.science/hal-01629249}

Submitted on 6 Nov 2017

HAL is a multi-disciplinary open access archive for the deposit and dissemination of scientific research documents, whether they are published or not. The documents may come from teaching and research institutions in France or abroad, or from public or private research centers.
L'archive ouverte pluridisciplinaire HAL, est destinée au dépôt et à la diffusion de documents scientifiques de niveau recherche, publiés ou non, émanant des établissements d'enseignement et de recherche français ou étrangers, des laboratoires publics ou privés. 


\title{
Protonation-Gated Dual Photochromism of a Chromene-Styryl Dye Hybrid
}

\author{
Daria V. Berdnikova, ${ }^{* \dagger, \dagger}$ Thomas Paululat, $^{\S}$ Gediminas Jonusauskas, ${ }^{\dagger} \quad$ Svetlana M. Peregudova, ${ }^{\dagger}$ \\ and Olga A. Fedorova ${ }^{\dagger}$ \\ ${ }^{\dagger}$ A. N. Nesmeyanov Institute of Organoelement Compounds, Russian Academy of Sciences, Vavilova 28, 119991 Moscow, Russia \\ ${ }^{\ddagger}$ Peoples Friendship University of Russia (RUDN University), Miklukho Maklaya 6, 117198 Moscow, Russia \\ ${ }^{\S}$ Universität Siegen, Organische Chemie II, Adolf Reichwein Str. 2, 57068 Siegen, Germany \\ "Laboratoire Ondes et Matière d'Aquitaine - UMR CNRS 5798, Bordeaux University, Talence 33405, France
}

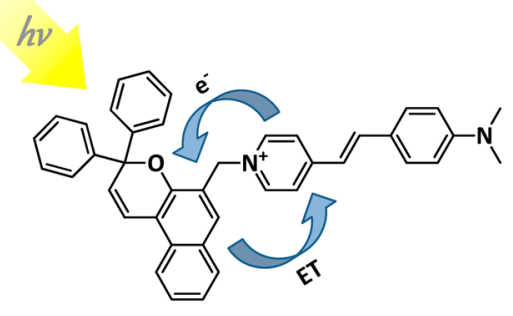

No photochromism

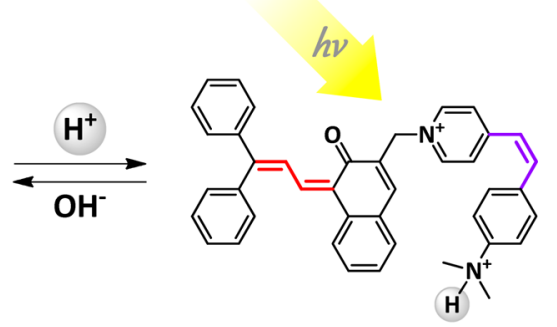

Dual photochromism

\begin{abstract}
A novel hybrid bisphotochromic system involving a chromene residue and a styryl dye fragment is described. Initially, the compound shows almost no photochromism due to intramolecular energy and electron transfer between the chromophores. Protonation of the hybrid system blocks the transfer processes and unlocks a dual photochromic activity that includes ring opening of the chromene fragment and $E Z$ isomerization of the styryl dye residue. Deprotonation of any photoinduced form resets the system to the initial photoinactive form.
\end{abstract}

Multiphotochromic systems represent an emerging field of photoactive compounds possessing high practical or creation of miniature molecular devices, logic gates, and high-density optical memory. ${ }^{1}$ The range of homodimeric and homomultimeric photochromes constructed of equal units is rather extensive, ${ }^{1}$ while examples of hybrid molecules comprising photochromic fragments of a different nature are still relatively limited because of increased complex-ity of their behavior. $^{2-19}$ At the same time, hybrid photo-chromes are especially useful as a platform for new smart materials and surfaces due to the possibility of orthogonal activation of photochromic entities and a greater number of available states. The majority of the reported hybrid photo-chromes is based on a dithienylethene moiety, and therefore, further development of these perspective compounds requires the use of other classes of photochromes.

In this work, we have designed and investigated novel hybrid bisphotochromic system 3 consisting of a chromene unit tethered to a styryl(pyridinium) dye fragment by a methylene linker (Scheme 1). Target compound 3 was obtained in $54 \%$ yield by interaction of bromoderivative $4^{20}$ with $p$ picoline followed by the Knoevenagel condensation of methylpyridi nium derivatized chromene $\mathbf{5}$ with $N, N$ dimethylamino benzaldehyde under alkaline conditions. New compounds 3
Scheme 1. Synthesis of Hybrid System 3 and Structures of Its Building Blocks 1 and 2

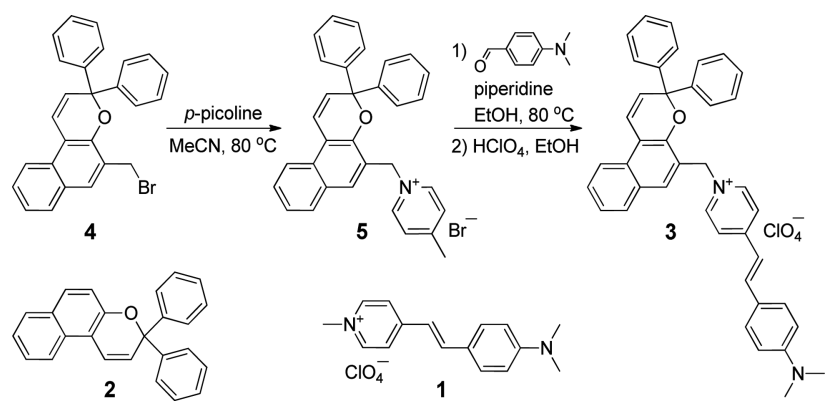

and 5 were fully characterized. In the free state, compound 3 showed almost no photochromism, whereas upon protonation of the dimethylamino group both chromophores in $3 \mathrm{H}^{+}$ became photoactive, thus demonstrating protonation gated dual photochromism.

It is known that styryl(pyridinium) dye $\mathbf{1}$, which is the first building unit of hybrid 3, is photochemically inert in polar 
solvents due to fast nonradiative relaxation through formation of TICT states (Twisted Intramolecular Charge Transfer). ${ }^{21,22}$ The second building unit is chromene 2 that upon UV irradiation undergoes electrocyclic $\mathrm{C}-\mathrm{O}$ bond cleavage followed by isomerization of the double bonds yielding two isomeric open forms TC (s trans-cis) and TT (s trans-trans). ${ }^{23}$ The closed form (CF) of 2 absorbs light in the UV $\left(\lambda_{\max }=315,350 \mathrm{~nm}\right)$, whereas absorption of the open forms (OF) is significantly shifted to the visible region $\left(\lambda_{\max }=430-460 \mathrm{~nm}\right)$, leading to formation of two spectroscopically clearly distinguishable states. The absorption spectrum of hybrid system 3 represents a superposition of its building block absorption with a moderate red shift of the styryl fragment absorption $\left(\lambda_{\max }=483 \mathrm{~nm}\right)$ in comparison to parent compound $1\left(\lambda_{\max }=471 \mathrm{~nm}\right)$ (Figure 1A). Notably, the absorption of the styryl dye residue at $350 \mathrm{~nm}$ is close to zero whereas the chromene absorption has a maximum at this wavelength providing a possibility of orthogonal excitation of the chromophores in 3.
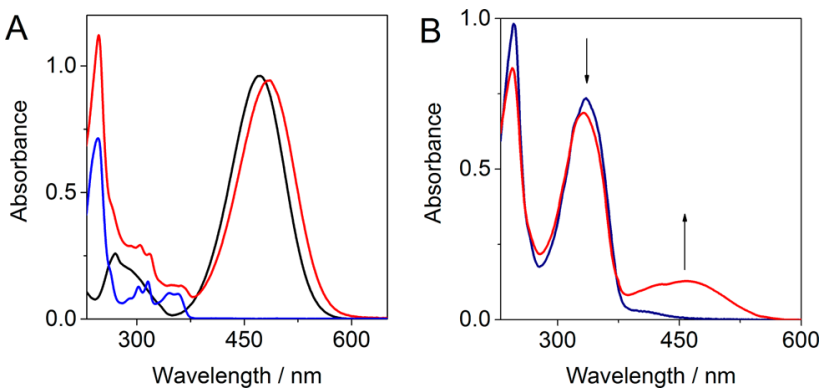

Figure 1. (A) Absorption spectra of hybrid system 3 (red) and parent compounds 1 (black) and 2 (blue) in $\mathrm{MeCN}$; in all cases $c=25 \mu \mathrm{M}$, $20{ }^{\circ} \mathrm{C}$. (B) Absorption spectra of the protonated hybrid system $3 \mathrm{H}^{+}$ (blue) and spectral changes upon irradiation of $3 \mathbf{H}^{+}$(red) in $\mathrm{MeCN}$, $c=21 \mu \mathrm{M}, 20^{\circ} \mathrm{C}$. The arrows indicate increasing absorption of the $\mathrm{OF}$ of the chromene fragment and decreasing absorption of the $Z$ isomer of the styryl dye residue upon irradiation.

Based on the photophysical properties of parent compounds 1 and 2, we expected that photoexcitation of hybrid system 3 in polar acetonitrile into the chromene absorption band would lead to the ring opening reaction of the chromene residue whereas the structure of the styryl fragment would remain unchanged. However, regardless of the excitation wavelength, compound 3 appeared to be almost photochemically inert and only showed very weak reversible changes of the absorption upon continuous irradiation. To clarify the reason for this behavior the steady state fluorescence of $\mathbf{3}$ was checked upon selective excitation of each chromophore. It was found that irrespective of the excitation wavelength, hybrid molecule 3 demonstrates the only fluorescence band centered at $630 \mathrm{~nm}$ that belongs to the styryl dye fragment. Additionally, the fluorescence excitation spectrum of 3 detected at the styryl residue emission maximum $(630 \mathrm{~nm})$ shows good coincidence with the absorption spectrum of hybrid system 3. Based on these data and considering good spectral overlap between fluorescence of $2^{24}$ and absorption of $\mathbf{1}$ (Figure $1 \mathrm{~A})$, we proposed the occurrence of the intramolecular energy transfer (ET) from the excited chromene unit to the styryl dye residue in $3 .^{25}$ The possibility of ET has also been supported by the relative positioning of the LUMO levels of each chromophore determined by cyclic voltammetry.
Thus, the energy difference between the LUMO of $\mathbf{2}$ (energy donor) and 1 (energy acceptor) is $\Delta E=-0.36 \mathrm{~V}$, which confirms thermodynamic feasibility of the energy transfer process in $3 .^{26}$ Additionally, the positions of the energy levels of $\mathbf{2}$ and $\mathbf{1}$ indicate the possibility of photoinduced electron transfer (PET) from the HOMO of the styryl chromophore to the $\mathrm{HOMO}$ of the chromene fragment upon excitation of the latter $(\Delta E=-0.48 \mathrm{~V})$.

A complete characterization of the energy and electron transfer processes in hybrid system 3 was obtained by transient absorption spectroscopy (TRABS). First, we performed a reference experiment, in which the styryl dye residue of 3 was directly excited into its absorption maximum at $490 \mathrm{~nm}$. The excitation kinetics of the styryl chromophore was not delayed and followed the temporal profile of the excitation pulse. Then we selectively excited the chromene moiety of 3 at $350 \mathrm{~nm}$. The styryl dye fragment does not absorb at $350 \mathrm{~nm}$ and, therefore, remained nonexcited. After the laser pulse, the excited state of chromene rapidly relaxed. In parallel, the initially nonexcited styryl dye fragment became excited indicating the transfer of the excitation from the chromene residue. The excitation kinetics of the styryl fragment was delayed in comparison with the reference experiment and occurred with the time constant of $\tau_{\mathrm{tr}}=0.12 \mathrm{ps}$ that characterizes the overall time frame of energy and electron transfer.

Treatment of the obtained data yielded the overall rate constant of the transfer processes $k_{\mathrm{tr}}=8.3 \times 10^{12} \mathrm{~s}^{-1}$. Assuming that the singlet excited state lifetime of CF of chromene 2 in acetonitrile is $\tau_{0}=0.45 \mathrm{ps}^{27}$ we estimated the ring opening rate constant to be $k_{\mathrm{ro}}=2.2 \times 10^{12} \mathrm{~s}^{-1}$. This means that the ET+PET processes in 3 occur about four times faster than the ring opening. Taking into account obtained rate constant values, we calculated the efficiency of the chromene ring opening in $\mathbf{3}$ as $\Phi_{\text {ro }}=21 \%$. Detailed analysis of the excited state decay kinetics of the styryl chromophore in 3 yielded efficiencies of the energy transfer $\Phi_{\mathrm{ET}}=63 \%$ and electron transfer $\Phi_{\mathrm{PET}}=16 \%$. This means that, upon selective photoexcitation of the chromene unit in 3 , the excitation energy is mainly forwarded to the styryl dye fragment through the ET channel that, together with the parallel PET process, significantly reduces the photochromic performance of the chromene residue. Notably, both Förster and Dexter mechanisms ${ }^{25}$ are involved in the energy transfer in 3.

Protonation of the dimethyamino group of hybrid 3 causes a pronounced blue shift of the styryl fragment absorption $(\Delta \lambda=-148 \mathrm{~nm})$ resulting in complete overlap of the absorption of both chromophores (Figure 1B). Such spectral changes indicate that the energy transfer in $3 \mathbf{H}^{+}$is not favored anymore. Complementary cyclic voltammetry studies showed that the energy gap between HOMO and LUMO in $\mathbf{1} \mathbf{H}^{+}\left(E_{0-0}\right.$ $=3.44 \mathrm{eV})$ exceeds that in $2\left(E_{0-0}=3.11 \mathrm{eV}\right)$, thus confirming that ET in $3 \mathbf{H}^{+}$is disabled. Since protonation of 3 blocks the lone electron pair on the dimethylamino nitrogen, the PET process from the protonated styryl fragment to chromene residue is also stopped. The drastic decrease in efficiency of the transfer processes unlocks the photochromic performance of 3 $\mathbf{H}^{+}$. Thus, irradiation of $3 \mathbf{H}^{+}$results in the appearance of the characteristic absorption of the chromene open forms in the visible region at $400-550 \mathrm{~nm}$ (Figure 1B). Additionally, absorption of $3 \mathbf{H}^{+}$at $335 \mathrm{~nm}$ 
Scheme 2. Overview of the Photochemical Transformations of Free Hybrid System 3 and Its Protonated Form $3 \mathrm{H}^{+}$

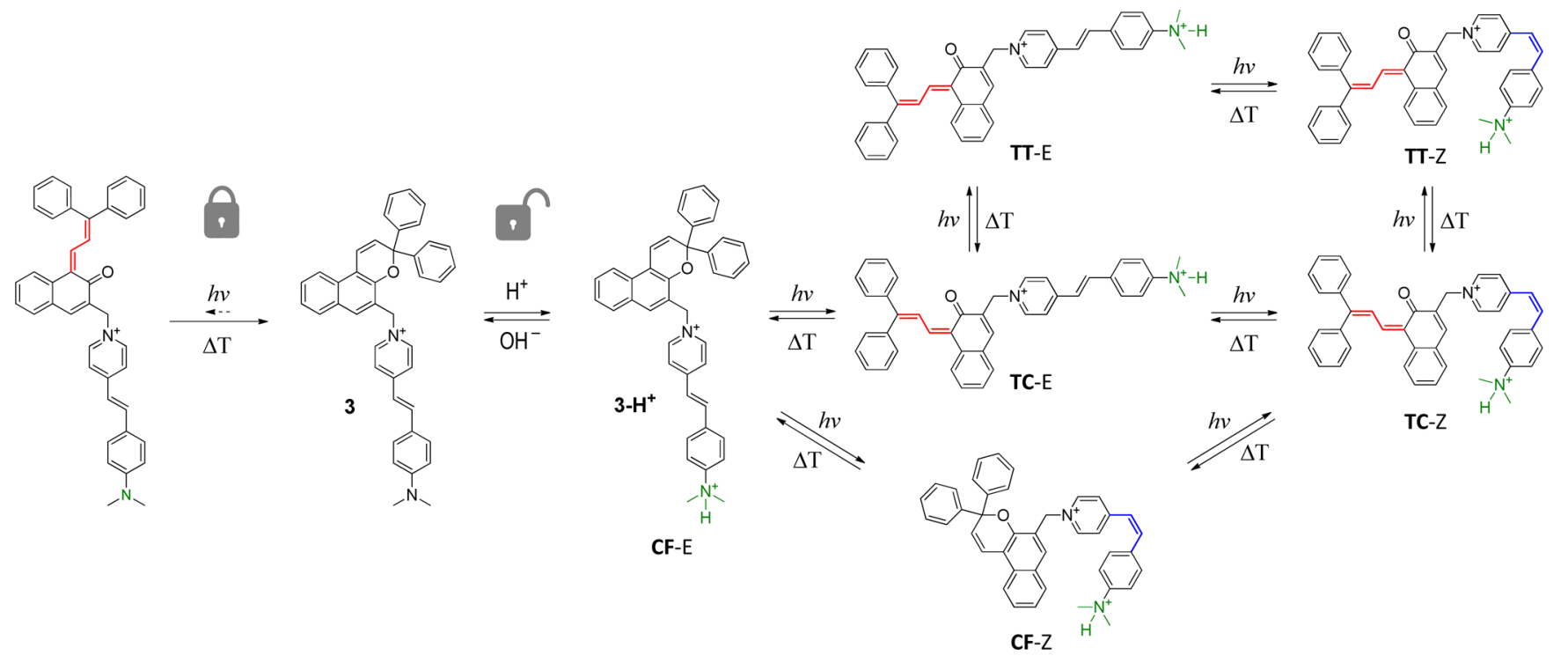

demonstrates a noticeable decrease that cannot be assigned with the chromene opening reaction. To explain this, we proposed the occurrence of the second photochemical transformation in protonated hybrid $3 \mathbf{H}^{+}$. As it was mentioned above, parent dimethylamino styryl(pyridinium) dye $\mathbf{1}$ is photochemically inactive in polar solvents. However, proto nation of the dimethylamino group in $\mathbf{1} \mathbf{H}^{+}$results in considerable loss of polarity of the molecule that favors photoinduced $E Z$ isomerization ${ }^{28}$ instead of the thermal relaxation through the TICT states. Changes in the spectral region of $300-350 \mathrm{~nm}$ observed during the photolysis of the protonated hybrid $3 \mathrm{H}^{+}$ strongly resemble the behavior of the protonated parent compound $\mathbf{1 ~ H}^{+}$in the course of $E Z$ photoisomerization. ${ }^{28}$ Therefore, there are two parallel photo chromic processes taking place in the protonated hybrid molecule $3 \mathbf{H}^{+}$, namely (i) chromene ring opening and (ii) $E Z$ isomerization of the styryl double bond. Both photochromic reactions are protonation gated and can be induced by light of the same wavelength.

To obtain a more detailed structural picture of the photochemical transformations, we performed NMR inves tigations upon continuous irradiation of the sample inside the NMR spectrometer. The $E Z$ isomerization of the protonated styryl fragment in $3 \mathbf{H}^{+}$can be clearly seen by the appearance of two doublets with the coupling constant of $J=12.4 \mathrm{~Hz}$ corresponding to the $Z$ conformation of the $\mathrm{C}=\mathrm{C}$ double bond. Unfortunately, due to the fast back reaction (see below), we were not able to detect the open form of chromene in this experiment even when lowering the temperature to $-40{ }^{\circ} \mathrm{C}$.

A principal scheme of the photochromic transformations of hybrid system 3 is depicted on Scheme 2. Protonation of the initial low active form 3 unlocks its photochemical activity. Thus, absorption of the first photon by the CF E form of $3 \mathbf{H}^{+}$ transfers the molecule into TC E or CF $\mathrm{Z}$ forms. Based on the absorption fraction of each photochromic unit of $3 \mathbf{H}^{+}$at 365 $\mathrm{nm}$ and the quantum yields of the corresponding photo reactions in $\mathrm{MeCN}$ (the ring opening of chromene 2: $\varphi_{\mathrm{ro}}=0.7$ $-0.9 j^{29}$ the $E Z$ isomerization of protonated styryl dye $1 \mathbf{H}^{+}$: $\varphi_{E-Z}=0.6$, we estimated that formation of the CF Z state occurs twice more efficiently compared to TC E. Further absorption of a photon by photoinduced TC E yields either TC Z or TT E species, whereas CF Z can transform only into TC Z. Finally, irradiation of TT E and TC $\mathrm{Z}$ results in the TT $\mathrm{Z}$ state. The back reactions of all photoinduced species occur thermally. The rate constant value for the reverse $Z E$ isomerization of the styryl residue in $3 \mathbf{H}^{+}$is $k_{\text {Z-E }}=0.5 \times 10^{-4} \mathrm{~s}^{-1}$. Considering the common thermal relaxation path for chromenes $(\mathrm{TT} \rightarrow \mathrm{TC} \rightarrow \mathrm{CF}){ }^{23}$ biexponential ring closure (bleaching) kinetics for the chromene unit in $3 \mathbf{H}^{+}$was expected. Nevertheless, the bleaching kinetics for $3 \mathbf{H}^{+}$were fitted to a monoexponential dependence with rate constant of $k_{\mathrm{rc}}=0.34 \mathrm{~s}^{-1}$. We explain this by a slow TC $\rightarrow$ TT reaction, when the observed kinetics virtually corresponds to the $\mathrm{TC} \rightarrow \mathrm{CF}$ transition. However, the TT form of the chromene residue of $3 \mathbf{H}^{+}$can be accumulated upon prolonged irradiation, which results in the residual coloration of the solution ${ }^{23}$ that persists for several days. Based on the above discussion, we conclude that formation of the TC Z species mainly takes place from the CF $\mathrm{Z}$ form as the latter decays much slower than TC E. To check the photochemical stability of the chromene residue in $3 \mathbf{H}^{+}$, w e recorded coloration -bleaching cycles that showed highly reproducible absorption intensity upon coloration and good thermal reversibility. Interestingly, the chromene ring closure in protonated hybrid $3 \mathbf{H}^{+}$occurs faster than in parent chromene 2 (cf. for $\left.2 k_{\mathrm{rc}}=0.25 \mathrm{~s}^{-1}\right)$. At the same time, the reverse $Z E$ isomerization in $3 \mathbf{H}^{+}$is slower than in parent dye $\mathbf{1 ~ H}^{+}$(cf. for $\left.1 \mathbf{H}^{+} k_{\mathrm{Z}-\mathrm{E}}=1.2 \times 10^{-4} \mathrm{~s}^{-1}\right)$. Nevertheless, close rate constant values for the corresponding photoprocesses in bischromophoric mole cule $3 \mathbf{H}^{+}$and its monochromophoric analogues $\mathbf{2}$ and $\mathbf{1} \mathbf{H}^{+}$ indicate that the chromophores in protonated $3 \mathrm{H}^{+}$behave almost independently, whereas in free 3 the chromophores represent an integral system due to the tight interaction within the ET and PET processes. Importantly, deprotonation of any photoinduced form of $3 \mathrm{H}^{+}$by addition of the base $\mathrm{NEt}_{4} \mathrm{OH}$ immediately switches the molecule back to the initial low active species 3 possessing the chromene residue in the closed form and the styryl double bond in the $E$ conformation. 
In summary, we have developed novel chromene-styryl dye hybrid 3 existing in two different modes. In the free state, the molecule undergoes efficient photoinduced energy and electron transfer between chromophores and, for this reason, exhibits virtually no photochromism (the "transfer" mode). Protonation switches the hybrid to the dual photochromic mode, in which both units demonstrate characteristic photochemical trans formations, i.e. ring opening/closure reaction of the chromene residue and reversible $E Z$ isomerization of the styryl dye fragment. Deprotonation of any photoinduced form of $3 \mathbf{H}^{+}$ provides a complete reset of the system to the initial weakly photochromic species 3. Obtained results outline an interesting approach toward creation of systems that can be easily switched between the photoinactive and dual photochromic state "on demand".

\section{AUTHOR INFORMATION}

\section{Corresponding Author}

*E mail: daria@ineos.ac.ru.

\section{ORCID}

Daria V. Berdnikova: 0000000207875753

Gediminas Jonusauskas: 0000000226471439

Olga A. Fedorova: 0000000178434157

Notes

The authors declare no competing financial interest.

\section{ACKNOWLEDGMENTS}

The publication was financially supported by the Ministry of Education and Science of the Russian Federation (Agreement No. 02.a03.0008) and RFBR 1503 04705. We thank Markus Rabe and Dr. Rainer Bornemann (Universität Siegen, Germany) for help to setup the "irradiation inside NMR". D.B. thanks Dr. Sergey Paramonov (INEOS RAS, Russia) for his friendly help and discussions on the chemistry of chromenes.

\section{REFERENCES}

(1) Fihey, A.; Perrier, A.; Browne, W. R.; Jacquemin, D. Chem. Soc. Rev. 2015, 44, 3719-3759.

(2) (a) Mrozek, T.; Görner, H.; Daub, J. Chem. Commun. 1999, 1487-1488. (b) Mrozek, T.; Görner, H.; Daub, J. Chem. Eur. J. 2001, 7, 1028-1040.

(3) Samat, A.; Lokshin, V.; Chamontin, K.; Levi, D.; Pepe, G.; Guglielmetti, R. Tetrahedron 2001, 57, 7349-7359.

(4) Gobbi, L.; Seiler, P.; Diederich, F.; Gramlich, V.; Boudon, C.; Gisselbrecht, J. P.; Gross, M. Helv. Chim. Acta 2001, 84, 743-777.

(5) Myles, A. J.; Wigglesworth, T. J.; Branda, N. Adv. Mater. 2003, 15, $745-748$.

(6) Choi, H.; Ku, B. S.; Keum, S. R.; Kang, S. O.; Ko, J. Tetrahedron 2005, 61, 3719-3723.

(7) (a) Frigoli, M.; Mehl, G. H. Angew. Chem., Int. Ed. 2005, 44, 5048-5052. (b) Delbaere, S.; Vermeersch, G.; Frigoli, M.; Mehl, G. H. Org. Lett. 2006, 8, 4931-4934.
(8) Kinashi, K.; Ono, Y.; Naitoh, Y.; Otomo, A.; Ueda, Y. J. Photochem. Photobiol., A 2011, 217, 35-39.

(9) Straight, S. D.; Liddell, P. A.; Terazono, Y.; Moore, T. A.; Moore, A. L.; Gust, D. Adv. Funct. Mater. 2007, 17, 777-785.

(10) Delbaere, S.; Vermeersch, G.; Frigoli, M.; Mehl, G. H. Org. Lett. 2010, 12, 4090-4093.

(11) Szalóki, G.; Sevez, G.; Berthet, J.; Pozzo, J. L.; Delbaere, S. J. Am. Chem. Soc. 2014, 136, 13510-13513.

(12) (a) Andréasson, J.; Straight, S. D.; Moore, T. A.; Moore, A. L.; Gust, D. J. Am. Chem. Soc. 2008, 130, 11122-11128. (b) Andréasson, J.; Pischel, U.; Straight, S. D.; Moore, T. A.; Moore, A. L.; Gust, D. J. Am. Chem. Soc. 2011, 133, 11641-11648.

(13) Bälter, M.; Li, S.; Nilsson, J. R.; Andréasson, J.; Pischel, U. J. Am. Chem. Soc. 2013, 135, 10230-10233.

(14) He, Y.; Zhu, Y.; Chen, Z.; He, W.; Wang, X. Chem. Commun. 2013, 49, 5556-5558.

(15) Geng, W.; Zheng, C.; Cui, S.; Liu, G.; Pu, S. J. Photochem. Photobiol., A 2014, 282, 47-52.

(16) Szalóki, G.; Alévêque, O.; Pozzo, J. L.; Hadji, R.; Levillain, E.; Sanguinet, L. J. Phys. Chem. B 2015, 119, 307-315.

(17) Erko, F. G.; Cseh, L.; Berthet, J.; Mehl, G. H.; Delbaere, S. Dyes Pigm. 2015, 115, 102-109.

(18) Gago, S.; Basílio, N.; Moro, A. J.; Pina, F. Chem. Commun. 2015, 51, 7349-7351.

(19) Levin, P. P.; Tatikolov, A. S.; Zaichenko, N. L.; Shienok, A. I.; Koltsova, L. S.; Sherbakova, I. M.; Mardaleishvili, I. R.; Berlin, A. A. Photochem. Photbiol. Sci. 2016, 15, 382-388.

(20) Samat, A.; Lokshin, V.; Chamontin, K.; Levi, D.; Pepe, G.; Guglielmetti, R. Tetrahedron 2001, 57, 7349-7359.

(21) Strehmel, B.; Seifert, H.; Rettig, W. J. Phys. Chem. B 1997, 101, 2232-2243.

(22) Cao, X.; Tolbert, R. W.; McHale, J. L.; Edwards, W. D. J. Phys. Chem. A 1998, 102, 2739-2748.

(23) Hepworth, J. D.; Heron, B. M. Photochromic Naphthopyrans. In Functional Dyes; Kim, S. H., Ed.; Elsevier: Amsterdam, 2006.

(24) Herzog, T. T.; Ryseck, G.; Ploetz, E.; Cordes, T. Photochem. Photobiol. Sci. 2013, 12, 1202-1209.

(25) Valeur, B. Molecular Fluorescence Principles and Application; Wiley VCH: 2001; pp 110-124.

(26) Mandal, A. K.; Suresh, M.; Das, P.; Das, A. Chem. Eur. J. 2012, $18,3906-3917$.

(27) Moine, B.; Réhault, J.; Aloïse, S.; Micheau, J. C.; Moustrou, C.; Samat, A.; Poizat, O.; Buntinx, G. J. Phys. Chem. A 2008, 112, 47194726.

(28) Gaines, G. L., Jr. Angew. Chem., Int. Ed. Engl. 1987, 26, 341-342.

(29) Görner, H.; Chibisov, A. K. J. Photochem. Photobiol., A 2002, $149,83-89$. 